Revista Brasileira de Cartografia

ISSN 1808-0936 | https://doi.org/10.14393/revbrascartogr

Sociedade Brasileira de Cartografia, Geodésia, Fotogrametria e Sensoriamento Remoto

\title{
Avaliação de Áreas Provedoras de Serviços Ambientais na APA Municipal do Rio Uberaba, Minas Gerais
}

\author{
Assessment of Environmental Service Provider Areas in the Municipal APA of the Uberaba \\ River, Minas Gerais
}

Aline Claro de Oliveira ${ }^{1}$, Julia Celia Mercedes Strauch ${ }^{2 \mathrm{e} 3}$, Amarildo da Cruz Fernandes ${ }^{4}$

1 Universidade Federal de Uberlândia, Programa de Pós-Graduação em Ecologia e Conservação dos Recursos Naturais, Uberlândia, Brasil. alineclarodeoliveira@gmail.com

ORCID: https://orcid.org/0000-0001-6088-9911

2 Escola Nacional de Ciências Estatísticas, Rio de Janeiro, Brasil. julia.strauch@ibge.gov.br

3 Universidade Federal Fluminense, Departamento de Análise Geoambiental, Niterói, Brasil. juliastrauch@id.uff.br

ORCID: http://orcid.org/0000-0002-9225-0511

4 Universidade Federal do Rio de Janeiro, Programa de Pós-Graduação em Engenharia Ambiental, Rio de Janeiro, Brasil. amarildo@poli.ufrj.br

ORCID: https://orcid.org/0000-0002-4550-4654

Recebido: 10.2019 | Aceito: 07.2020

Resumo: A criação de Programas de Pagamentos por Serviços Ambientais (PSA) é uma das políticas públicas que vem sendo adotadas para alinhar os interesses de proprietários de terras que se encontram localizadas em bacias hidrográficas que possuem mananciais utilizados para abastecimento público, aos interesses das companhias de água. Este trabalho objetiva identificar áreas provedoras do serviço ambiental que apresentam controle da erosão na Área de Proteção Ambiental (APA) municipal do rio Uberaba, criada para proteger o manancial de abastecimento público do município de Uberaba, MG. Para isso é utilizado o módulo de retenção de sedimentos do sistema InVEST (Integrated Valuation of Ecosystem Services and Tradeoffs), que utiliza como base a Equação Universal de Perda de Solo e criado um cenário hipotético em que as Áreas de Preservação Permanente (APPs) foram reflorestadas de acordo com a Lei 12.651/2012. Isto permitiu comparar os resultados da modelagem do cenário do ano de 2016 com o cenário hipotético. Como resultado identificou-se que as microbacias da APA municipal do rio Uberaba foram classificadas com perdas de solos médias $(61 \%)$, média forte $(27 \%)$, forte $(2 \%)$, nula a pequena $(6 \%)$ e moderada $(4 \%)$. De acordo com a modelagem do InVEST, o total de sedimentos estimados pelas microbacias que compõem a APA municipal do rio Uberaba em 2016 foi de 2.620.062 ton/ano e para o cenário futuro foi de 1.258.989 ton/ano. Esse resultado indica que a recuperação de cerca de $6 \mathrm{~km}^{2}$ de APPs pode reduzir a geração de sedimentos em $48 \%$.

Palavras-chave: Recursos Hídricos. Cenários. InVEST

\begin{abstract}
The creation of Payments for Ecosystem Services (PSE) Programs is an example of public policy that has been adopted to align the interests of landowners whose lands are located in river basins, which contain water sources used for public supply, and the interests of water companies. This work aims to identify areas that provide environmental services that present erosion control in the Municipal Environmental Protection Area (APA) of the Uberaba River, created to protect the public supply source in the municipality of Uberaba, MG. To do so, the sediment retention module of the software InVEST (Integrated Valuation of Ecosystem Services and Tradeoffs) is used, based on the Universal Soil Loss Equation (USLE) and created a hypothetical scenario, in which the Permanent Preservation Areas (PPAs) located within the EPA were reforested according to Law 12.651/2012. This allowed the comparison between the modeling results from the 2016 scenario with the hypothetical scenario. As a result, it was identified that the micro basins of the municipal EPA of the Uberaba River were classified with the following soil loses, medium $(61 \%)$, medium-strong (27\%), strong (2\%), small to null $(6 \%)$ and moderate $(4 \%)$. According to the modelling of the InVEST software, the total sediments estimated for the micro basins that compose the municipal APA of the Uberaba River in 2016 was 2,620,062 tons/year and for the future scenario was 1,258,989 tons/year. This result indicates that the recovery of about $6 \mathrm{~km}^{2}$ of PPAs can reduce sediment generation by $48 \%$.
\end{abstract}

Keywords: Water resources. Scenarios. InVEST. 


\section{INTRODUÇÃO}

A criação de Programas de Pagamentos por Serviços Ambientais (PSA) é uma das políticas públicas que vem sendo adotadas para alinhar os interesses de proprietários de terras que se encontram localizadas em bacias hidrográficas que possuem mananciais utilizados para abastecimento público, aos interesses de companhias de água.

De acordo com Zolin (2010), países como Costa Rica, El Salvador, Equador, Peru, Guatemala, Colômbia, EUA, Espanha e Itália já possuem sistemas de PSA em bacias hidrográficas implantados. No Brasil, o caso pioneiro é o do município de Extrema, em Minas Gerias. O programa denominado Conservador das Águas, foi a primeira iniciativa municipal de implantação de PSA, que se baseia na relação existente entre a floresta e os serviços prestados por ela referente à conservação do solo, quantidade e qualidade da água (ZOLIN, 2010).

O PSA é um tipo de transferência financeira dos beneficiários para aqueles que, por meio de suas atividades e práticas, conservam a natureza (SILVA, 2011). Também são chamados de compensação ou arrendamento, em que os proprietários das terras que proporcionam os serviços hídricos são beneficiados ao adotar medidas de conservação do uso da terra (QUINTERO, 2010). Para Wunder (2013), o PSA é uma ferramenta bastante exigente, demandando uma cultura de pagamento e uma boa organização dos usuários dos serviços.

Antes de implantar um PSA em determinada área, seu verdadeiro potencial deve ser estudado. Como afirma Ferraro (2011), a auto seleção adversa, ou seja, aquela que é voluntária, pode direcionar os pagamentos para terras de baixo valor ambiental. De acordo com Muradian et al. (2010), o contexto em que a maioria dos esquemas de PSA operam é muitas das vezes caracterizada por elevada incerteza na prestação de contas de serviços ambientais, devido às complexidades biofísicas associadas às relações entre o uso da terra e esses serviços.

A devastação do Cerrado, nas últimas décadas, vem se tornando uma ameaça à provisão dos serviços ambientais deste bioma. Nesse sentido, são necessários estudos que promovam o pagamento por serviços ambientais para investigar o uso de forma sustentável dos recursos naturais nesse bioma.

A Área de Proteção Ambiental (APA) municipal do Rio Uberaba, inserida no Cerrado, é uma potencial área de estudos, pois é um local de interesse estratégico para o município de Uberaba, uma vez que o rio Uberaba, o único manancial de abastecimento público do município, se encontra nesta unidade de conservação. O rio Uberaba no período da seca já não consegue atender à demanda, problemática que vem se agravando a cada ano devido aos impactos ambientais que estão ocorrendo ao longo de seu curso, especialmente pelo uso indiscriminado da irrigação (CÂNDIDO et al., 2010). Uma alternativa ao conflito de uso da água que se encontra instalado seria a implantação de um Programa de PSA, sendo necessários estudos que orientem o Poder Público no planejamento e na tomada de decisões. Diante do exposto, este trabalho tem por objetivo identificar áreas provedoras do serviço ambiental que apresentam controle da erosão, utilizando um modelo de retenção de sedimentos baseado na Equação Universal de Perda de Solo.

\section{2 ÁREA DE ESTUDO}

A APA Municipal do Rio Uberaba está localizada no município de mesmo nome, Uberaba, na microrregião do Triângulo Mineiro, no estado de Minas Gerais, e ocupa uma área de $520 \mathrm{~km}^{2}$, cerca de $11 \%$ do município conforme ilustrado na Figura 1. O município de Uberaba possui uma área de 4.523,957 km² e está totalmente inserido no bioma Cerrado e dista cerca de $500 \mathrm{~km}$ da capital mineira. A unidade de conservação é cruzada pelo centro pela Rodovia MG-427, numa extensão de aproximadamente $25 \mathrm{~km}$, na sua parte inferior é tangenciada pela Rodovia BR-262, próxima à região da nascente do rio Uberaba e a 3,5km, sentido oeste, tem a Rodovia BR-050 (Figura 2).

A APA municipal do rio Uberaba corresponde ao alto curso do rio Uberaba (UBERABA, 2004) que da nascente a foz percorre cerca de $140 \mathrm{Km}$ até desaguar no rio Grande, inserido na Região Hidrográfica do Paraná. $\mathrm{O}$ rio Uberaba nasce numa região de covoal à nordeste do município, próximo ao trevo que dá acesso 
ao bairro de Ponte Alta, na rodovia BR-262, quilômetro 756, na altitude de 1012 m (OLIVEIRA, 2005) e percorre $55 \mathrm{~km}$ da nascente até a estação de captação do município (CODAU, 2005), conforme destacado na Figura 3.

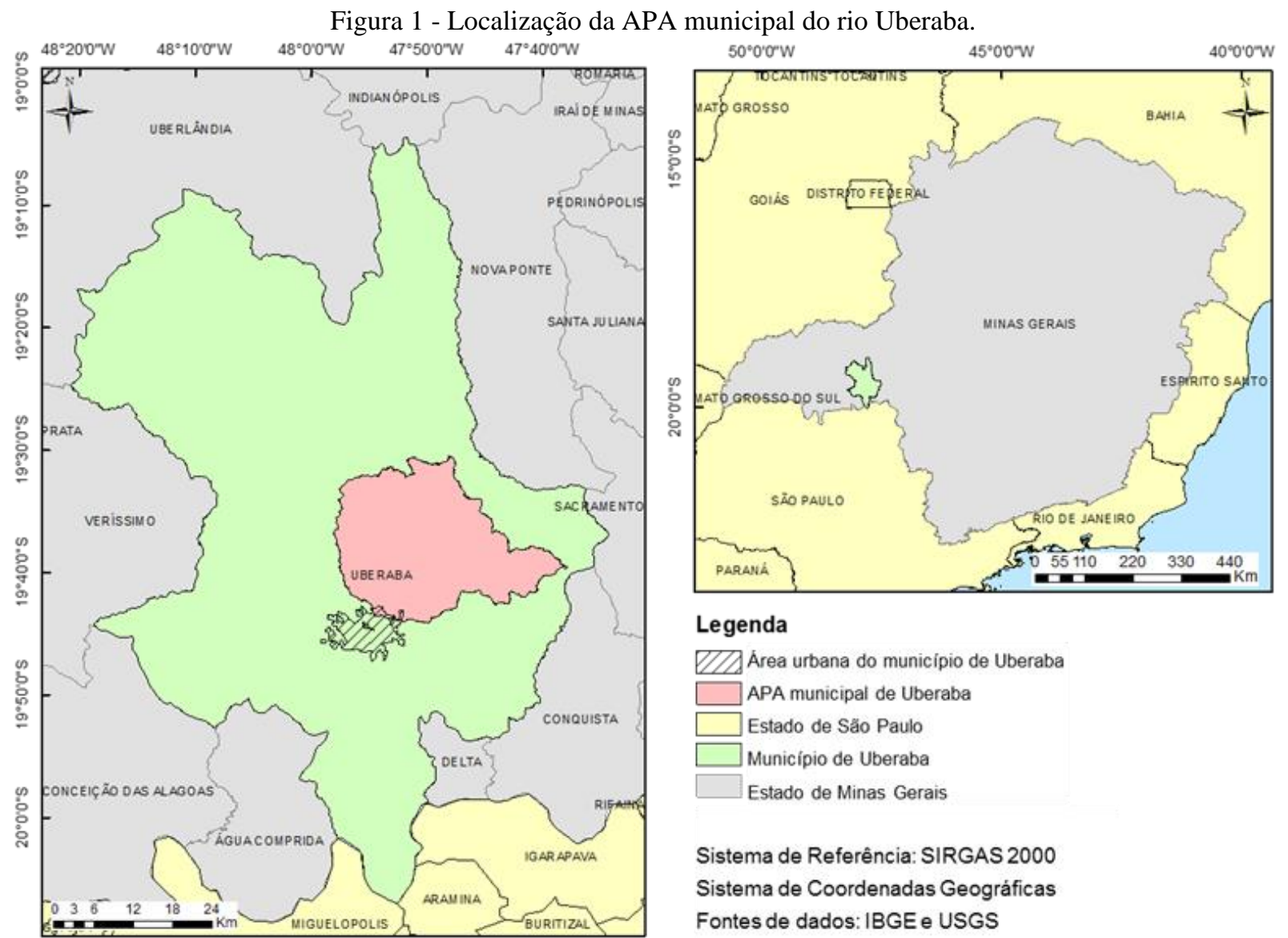

Fonte: Os autores (2021).

Figura 2 - Rodovias e linhas férreas na APA municipal do rio Uberaba.

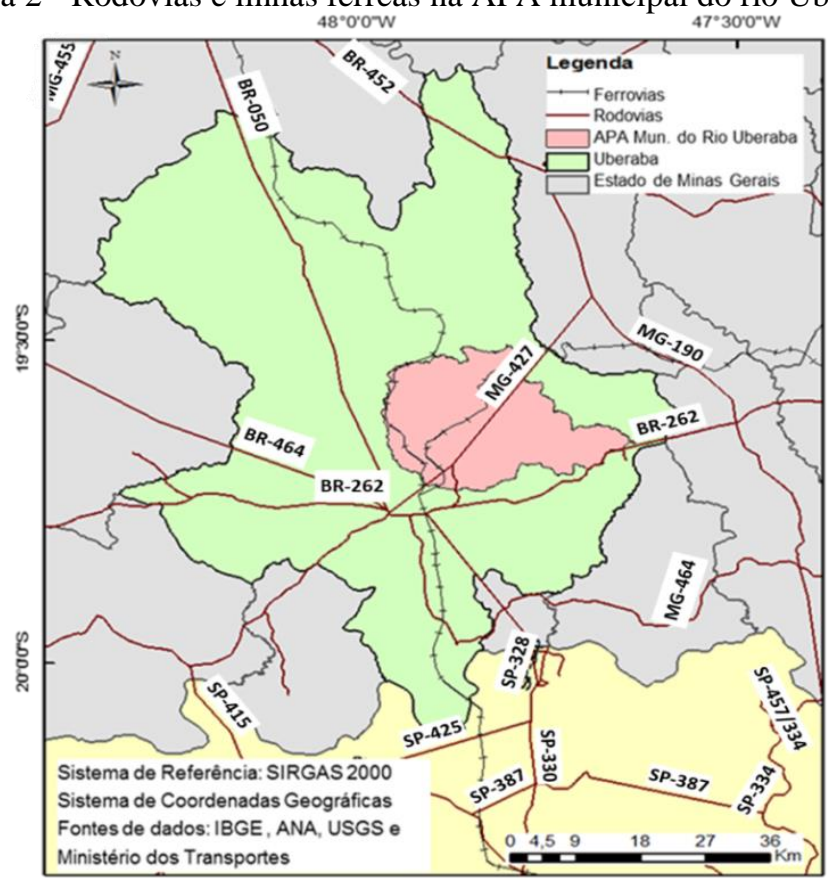

Fonte: Os autores (2021).

O covoal está associado a condições de má drenagem, compondo as bordas das veredas, comuns nas áreas de cerrado e, normalmente associadas a nascentes (PEDROSO NETO; COSTA, 2010). Os covoais 
também são caracterizados como campos hidromórficos, ou seja, campos inundados de água, que funcionam como esponjas que absorvem a água das chuvas e a liberam lentamente durante o ano, atuando como um grande reservatório (UBERABA, 2004).

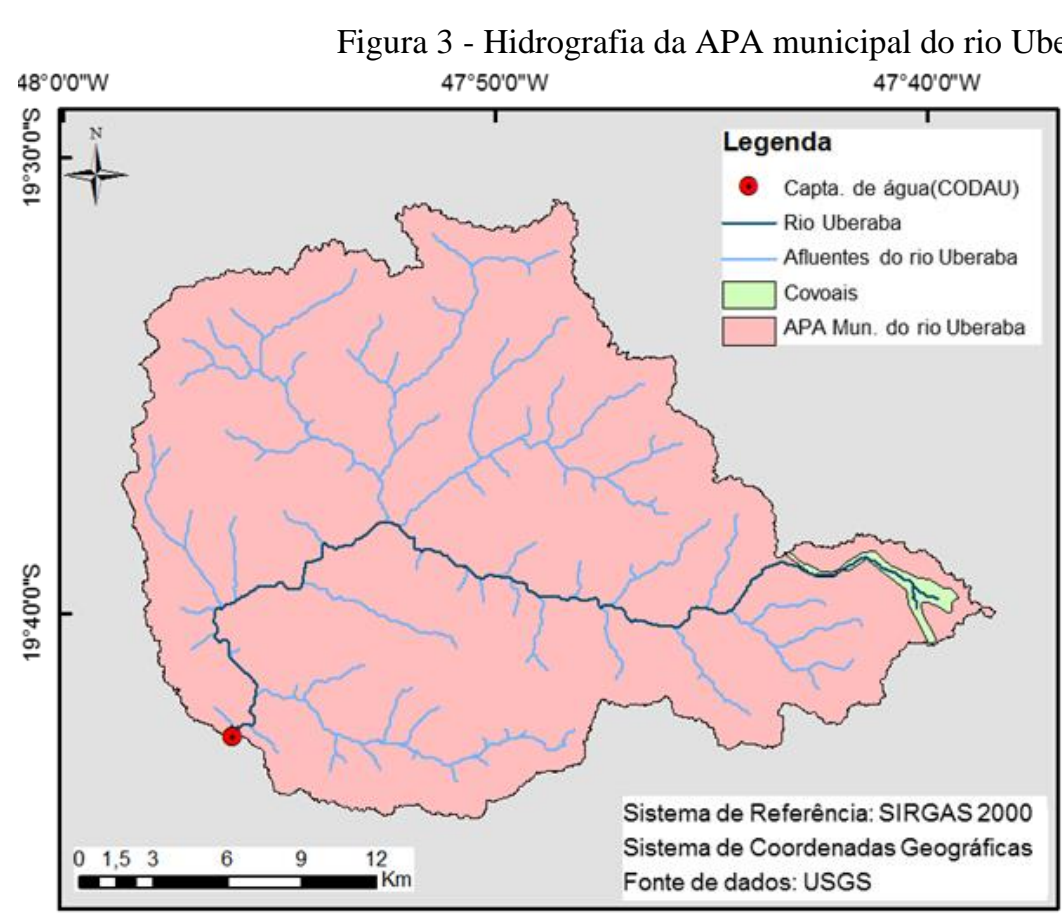

Fonte: Os autores (2021).

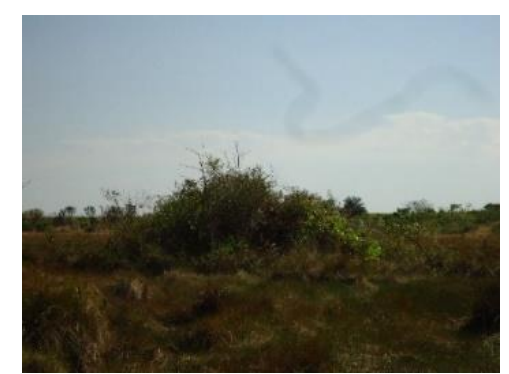

a) Nascente do rio Uberaba

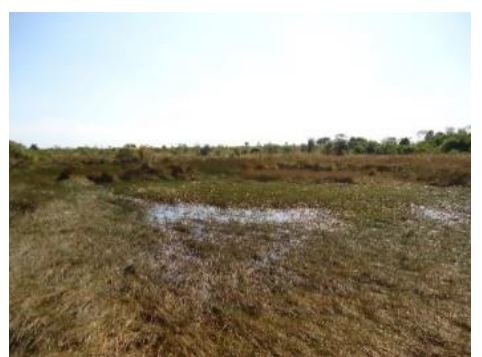

b) Área inundada no covoal

A área de covoais, apresentadas nas Figuras 3a e 3b, é constituída por uma área plana, inundável no período das chuvas, onde se encontram inúmeros morrotes. Esses covoais têm grande importância ecológica no ciclo hidrológico dessas regiões (UBERABA, 2012).

Abdala et al. (2009) caracterizam o sistema de drenagem com padrão dendrítico e as altitudes variam de 750 a $1000 \mathrm{~m}$, possuindo relevo suave ondulado, com declividade predominante menor que 10\%. Estes autores após gerarem o mapa de isoconcentração das nascentes da APA municipal do rio Uberaba, observaram que ocorre um maior número de nascentes concentradas nas áreas de maior altitude, na chapada ou nas proximidades desta, concluindo que a sustentação hídrica do rio Uberaba no período da seca é feita pelos córregos que tem nascentes na borda da chapada. No entanto a recarga hídrica dos córregos da APA municipal do rio Uberaba pode estar sendo ameaçada devido a substituição da vegetação nativa pela monocultura de cana-de-açúcar nessas áreas de chapada.

Um problema identificado por Candido et al. (2010) é o potencial natural de erosão alto, muito alto e extremamente alto nas áreas de nascentes localizadas na APA municipal do rio Uberaba. Valle Júnior (2008) ressalta que os prejuízos sociais e ambientais gerados pela erosão são bastante elevados e os principais fatores relacionados com o aumento da degradação ambiental estão as frequentes alterações não planejadas no uso da terra, acima da capacidade de suporte do solo. Barrella et al. (2009) destacam a importância da cobertura vegetal para os cursos de água localizados em cabeceiras, por serem considerados frágeis. Segundo esses autores, a vegetação é de extrema importância para sua preservação, pois evita a erosão dos solos adjacentes, impedindo a sedimentação ou assoreamento do leito do rio. Eles destacam que em média um terreno de um hectare descoberto chega a transportar 16 toneladas de solo por ano.

\section{MATERIAL E MÉTODOS}

Para identificar as áreas provedoras e beneficiadas pelos serviços ecossistêmicos na APA municipal do rio Uberaba foi utilizado o InVEST (Integrated Valuation of Ecosystem Services and Tradeoffs). Trata-se de um sistema gratuito da Stanford University (2013) que oferece um conjunto de modelos com código aberto 
usado para modelar, mapear e valorar os bens e serviços ambientais. Segundo Garrastazu et al. (2012), é um dos programas mais promissores para modelagem de serviços ambientais.

O InVEST oferece dezoito modelos distintos de serviços ecossistêmicos. O módulo empregado nesse trabalho foi o modelo de retenção de sedimentos que tem como base a Equação Universal da Perda de Solo (EUPS) apresentada na Eq. (1) (MATOS, 2015). Este modelo calcula a perda de solo média anual de cada parcela de terra, determina o quanto de solo pode chegar a um determinado ponto de interesse, possibilita conhecer a capacidade de cada parcela para reter sedimentos, além de poder estimar o custo de sua remoção.

$$
A=R \cdot K \cdot(L . S) \cdot(C . P)
$$

onde:
$A=$ perda média anual de solo por unidade de
$L=$ comprimento da vertente;
área (ton/ha.ano);
$S=$ declividade da vertente;
$R=$ erosividade da chuva (Mj.mm/ ha.h.ano);
$C=$ uso e manejo do solo; e
$K=$ erodibilidade do solo;
$P=$ práticas conservacionistas

Neste trabalho para identificar as áreas provedoras do serviço ambiental de controle da erosão na APA municipal do rio Uberaba foram utilizados os seguintes dados: imagens do satélite Landsat 8 e Modelo Digital de Elevação (MDE) do United States of Geologic Survey (USGS), Limites municipais e estaduais do Instituto Brasileiro de Geografia e Estatística (IBGE), arquivos vetoriais das rodovias e ferrovias do Ministério dos Transportes, arquivos vetoriais da hidrografia da Agência Nacional das Águas, limite da APA municipal do rio Uberaba da Secretaria de Meio Ambiente de Uberaba e o mapa de solos de Minas Gerais da Universidade Federal de Viçosa (UFV). A imagem Landsat 8 selecionada foi a do sensor OLI, com órbita/ponto 220/74, resolução espacial de 30 metros e resolução radiométrica de 12 bits, reescalonado para 16 bits. $\mathrm{O}$ critério para sua seleção considerou uma porcentagem igual ou inferior a $10 \%$ de cobertura de nuvens. A cena adquirida para esta pesquisa foi tomada em 09/04/2016, e esta data foi selecionada no mês de abril por estar no período seco.

Para se atingir os objetivos o trabalho consistiu em três etapas distintas: obtenção dos dados de entrada do modelo; alimentação do modelo; e avaliação da mensuração de cenários (Figura 4).

Figura 4 - Etapas para obtenção, avaliação e mensuração de cenários.

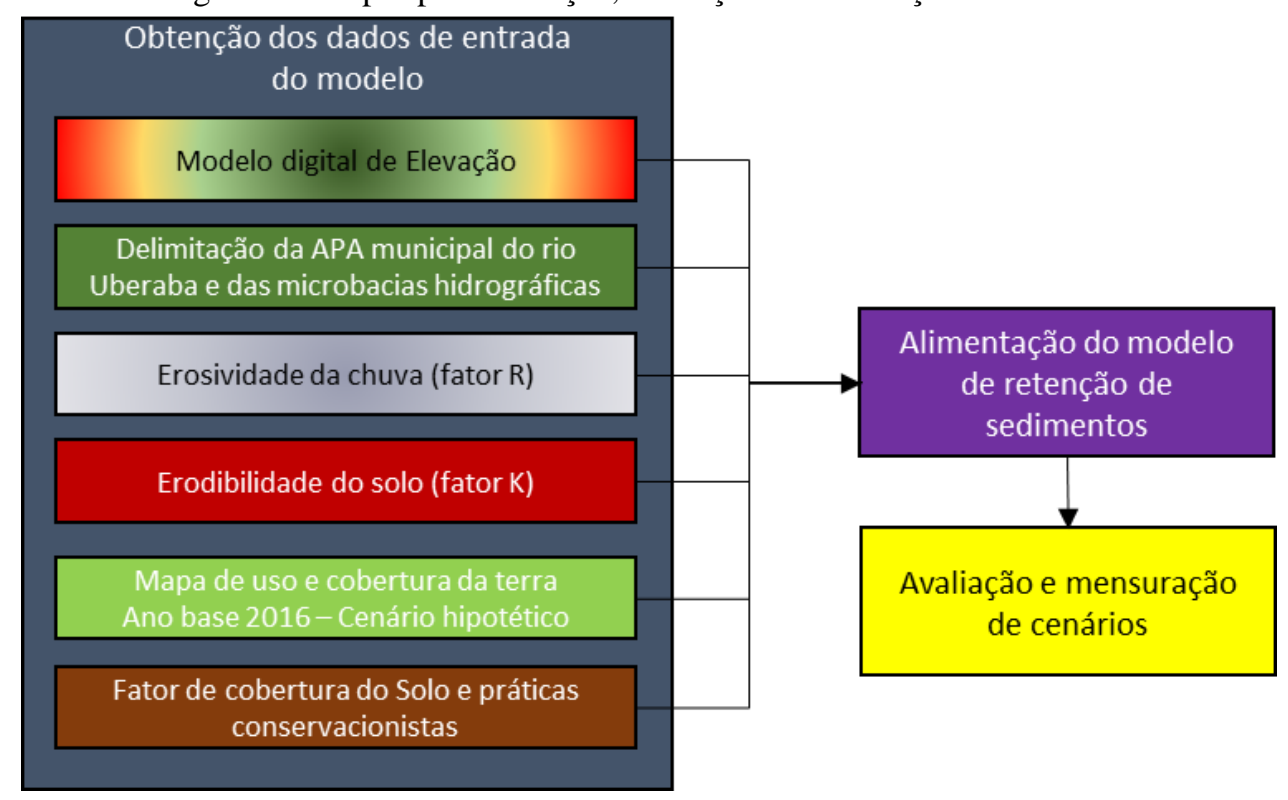

Fonte: Os autores (2021).

Para a obtenção do mapa de erosividade da APA municipal do rio Uberaba adotou-se a metodologia proposta por Matos (2015), que utiliza o programa computacional NetErosividade MG 
(http://www.gprh.ufv.br/) da Universidade Federal de Viçosa (UFV). Trata-se de um programa computacional que permite estimar o valor da erosividade da chuva mensal e anual da intensidade máxima da chuva em trinta minutos (EI30') para qualquer localidade do Estado de Minas Gerais (MOREIRA et al., 2008).

Cabe destacar ainda que para a obtenção do mapa de uso e cobertura da terra foram utilizadas as bandas 4, 5 e 6 do Landsat 8 na composição 6R5G4B a fim de obter uma composição colorida falsa cor e foram identificadas as seguintes classes na área de estudo: covoais, vegetação natural (remanescentes florestais ao longo dos cursos d'água), agricultura estágio inicial (cultura de cana-de-açúcar em fase de brotação), agricultura estágio avançado (cultura de cana-de-açúcar pronta para a colheita), solo exposto 1 (solo com tons de roxo), solo exposto 2 (solo com tons de vermelho escuro), solo exposto 3 (solo com tons de vermelho claro), pastagem, área urbanizada e construída. Nesse trabalho foi utilizada a estratégia de considerar três classes de solo uma vez que em teste prévio, com apenas uma classe de solo, verificou-se uma confusão espectral dos alvos, ficando a imagem mal classificada.

O método de classificação empregado foi a supervisionada pixel-a-pixel, pelo método da Máxima Verossimilhança (Maxver). Este método utiliza amostras de treinamento representativas das classes a serem mapeadas de forma a extrair das imagens os grupamentos mais homogêneos que compõem uma unidade de mapeamento ou o polígono. As amostras foram selecionadas visualmente nas imagens baseadas no conhecimento prévio de uma visita de campo para conhecimento da área.

Após a validação foi aplicado o filtro majoritário para agrupar pixels com a mesma similaridade e executada a reclassificação da imagem, onde foram definidas as classes utilizadas para a confecção do mapa de uso e cobertura da terra (Figura 7). O Quadro 1 mostra quais classes foram identificadas inicialmente e as classes após a reclassificação.

Quadro 1 - Classes identificadas e reclassificação.

\begin{tabular}{|c|c|c|}
\hline Classes identificadas & Classes reclassificadas & Descrição \\
\hline Área urbanizada e construída & Área urbana & Área urbana e vias pavimentadas \\
\cline { 1 - 1 } Solo exposto 1 (tons de vermelho escuro) & Solo exposto & $\begin{array}{c}\text { Áreas agrícolas que foram aradas e } \\
\text { se encontram temporariamente com } \\
\text { o solo exposto }\end{array}$ \\
\cline { 1 - 1 } Solo exposto 2 (tons de roxo) & Agricultura & $\begin{array}{c}\text { Áreas destinadas à agricultura anual } \\
\text { ou não }\end{array}$ \\
\cline { 1 - 1 } Solo exposto 3 (tons de vermelho claro) & Pastagem & $\begin{array}{c}\text { Áreas cobertas por capim } \\
\text { destinadas ao pastoreio do gado }\end{array}$ \\
\cline { 1 - 1 } Agricultura estágio inicial & Vegetação natural & $\begin{array}{c}\text { Áreas de remanescentes florestais, } \\
\text { matas ciliares }\end{array}$ \\
\hline Agricultura estágio avançado & Pastagem &
\end{tabular}

Fonte: Os autores (2021).

Para o desenvolvimento do trabalho foram utilizados ainda o ambiente de sistemas de informações geográficas ArcGIS Desktop 10.1 da ESRI, Word e Excel da Microsoft, Google Earth da Google. Para coleta dos pontos de validação foi utilizado GPS portátil Garmin eTrex.

\subsection{Obtenção Modelo Digital de Elevação}

O Modelo Digital de Elevação (MDE) é um dado na estrutura matricial com o valor de elevação para cada célula obtido a partir do Shuttle Radar Topography Mission (SRTM) e editado no ArcGIS 10.1. Tendo em vista as recomendações do Manual do InVEST 3.3.3, as depressões que representam um empecilho ao escoamento durante a aplicação de modelos hidrológicos, sedimentológicos e de poluentes de origem difusa foram corrigidas pela ferramenta fill sinks. De acordo com Planchon e Darboux (2002), essa ferramenta considera as altitudes dos pixels vizinhos para preencher as depressões presentes no MDE.

Cabe destacar que o fator topográfico (Fator LS) que avalia a influência do relevo no risco de erosão considerando a extensão de vertentes e as classes de declividade de forma a identificar áreas mais susceptíveis à dinâmica erosiva foi obtido a partir do Modelo Digital de Elevação (MDE), sendo calculado diretamente no InVEST usando o módulo SDR (Sediment Delivery Ratio) (THOMPSON; FIDALGO, 2013).

Para a delimitação das microbacias hidrográficas, que foram analisadas quanto à produção e retenção de sedimentos para um determinado ponto de interesse foi utilizado a ferramenta ArcHydro do ArcGis 10.1, 
que delimita de forma automática a rede de drenagem, as bacias e microbacias hidrográficas a partir do MDE, a partir da seguinte sequência de passos:

1. Preenchimento de pequenas imperfeições nos dados e remoção de todas as depressões considerando as altitudes dos pixels vizinhos;

2. Cálculo a direção do fluxo em oito direções tomando por base a linha de maior declividade do terreno, gerando como saída uma grade regular que define as direções de fluxo;

3. Cálculo do fluxo acumulado obtido somando-se a área das células na direção do fluxo, representando assim a rede hidrográfica;

4. Definição da rede de drenagem para o MDE utilizando um limiar para acumulação de fluxo, que neste trabalho, o especificado foi 1000;

5. Geração de uma grade de captação contendo o delineamento da rede de drenagem combinado com o fluxo;

6. Conversão da grade de captação em uma classe de recurso de polígono de captação;

7. Processamento da linha de drenagem atribuindo um identificador da bacia em que reside;

8. Processamento das bacias adjacentes, considerando as captações de fluxo ascendente de modo que para cada microbacia um polígono represente toda a área de drenagem da área a montante;

9. Geração dos pontos de drenagem associados às microbacias hidrográficas;

10. Inserção de um bath point nas coordenadas do ponto de captação de água do CODAU (2005) e treze bath points na foz do corpo hídrico para cada uma das treze bacias hidrográficas; e

11. Delimitação da APA municipal do rio Uberaba e as outras 13 microbacias que compõe a área de estudo.

\subsection{Obtenção do mapa de erosividade da APA municipal do rio Uberaba}

Para a elaboração do mapa de erosividade da APA municipal do rio Uberaba foram estimadas pelo programa NetErosividade MG o valor da erosividade da chuva mensal e anual da intensidade máxima da chuva em trinta minutos, obtidas as coordenadas das estações pluviométricas existentes no contexto da área de estudo e, em seguida, interpolados no ambiente ArcGis para obtenção do mapa na estrutura raster com o valor do índice de erosividade para região (Figura 5).

Figura 5 - Erosividade da APA municipal do rio Uberaba.

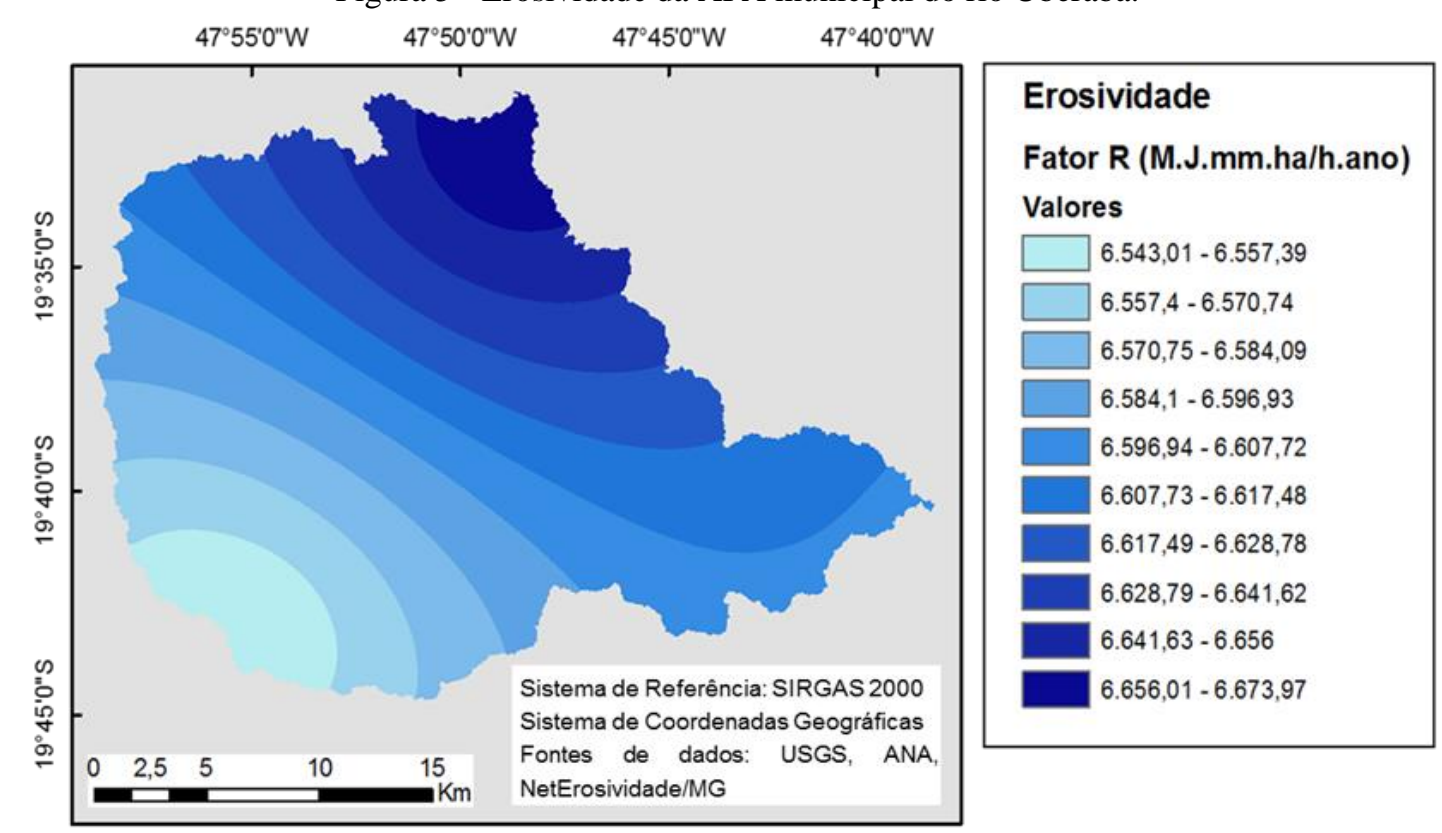

Fonte: Os autores (2021).

A erosividade determinada para a área de estudo possui valores entre 6.543,01 a 6.656,01 M.J.mm.ha /h.ano. Segundo a chave de interpretação proposta por Carvalho (1994 apud MATOS, 2015), descrita na Tabela 1, os valores alcançados são classificados como média-forte. Valle Júnior (2008) calculou o valor médio anual 
da erosividade, referente a bacia hidrográfica do rio Uberaba, entre os anos de 1999 e 2005, e obteve o valor de 7.846,54 MJ.mm.ha/h.ano. Cabe destacar que este valor que depende da duração e intensidade da chuva para a região.

Tabela 1 - Classe de interpretação da erosividade da chuva.

\begin{tabular}{ll}
\hline M.J.mm.ha/ h.ano & Classe \\
\hline $\mathrm{R} \leq 2452$ & Baixa \\
$2452<\mathrm{R} \leq 4905$ & Média \\
$4905<\mathrm{R} \leq 7357$ & Média - forte \\
$7357<\mathrm{R} \leq 9810$ & Forte \\
$\mathrm{R}>9810$ & Muito forte \\
\hline
\end{tabular}

Fonte: Carvalho (1994) e Silva (2004) apud Matos (2015).

De acordo com Valle Júnior (2008), para a bacia hidrográfica do rio Uberaba, o período de novembro a março representa maior risco erosivo, enquanto nos meses de abril a setembro não há elevação da inclinação das curvas de distribuição dos valores médios da erosividade anual. Isto é, esses meses apresentam menor risco erosivo.

\subsection{Obtenção do mapa de erodibilidade da APA municipal do rio Uberaba}

A erodibilidade da APA municipal do rio Uberaba foi obtida a partir do mapa de solos elaborado pela Universidade Federal de Viçosa (UFV, 2010), na escala de 1:600.000, ilustrado na Figura 6. A erodibilidade na área de estudo variou entre 0,01625 e 0,04825 Mg ha HJ-1 mm-1.

Segundo a chave de interpretação adaptada de Carvalho (1994 apud MATOS, 2015), descrita na Tabela 2, a maior parte da bacia é composta predominantemente por solos de baixa erodibilidade (72\%) onde a classe de solo é o Latossolo, os restantes são classificados como alta erodibilidade (25\%), onde a classe de solo é o Argissolo e apenas 3\% é classificado com erodibilidade média, onde a classe de solo é o Gleissolo. De acordo com Matos (2015), os Latossolos são os mais resistentes, pois além de possuírem alto grau de estabilidade e alta porosidade e permeabilidade, geralmente são bem drenados, profundos e coesos.

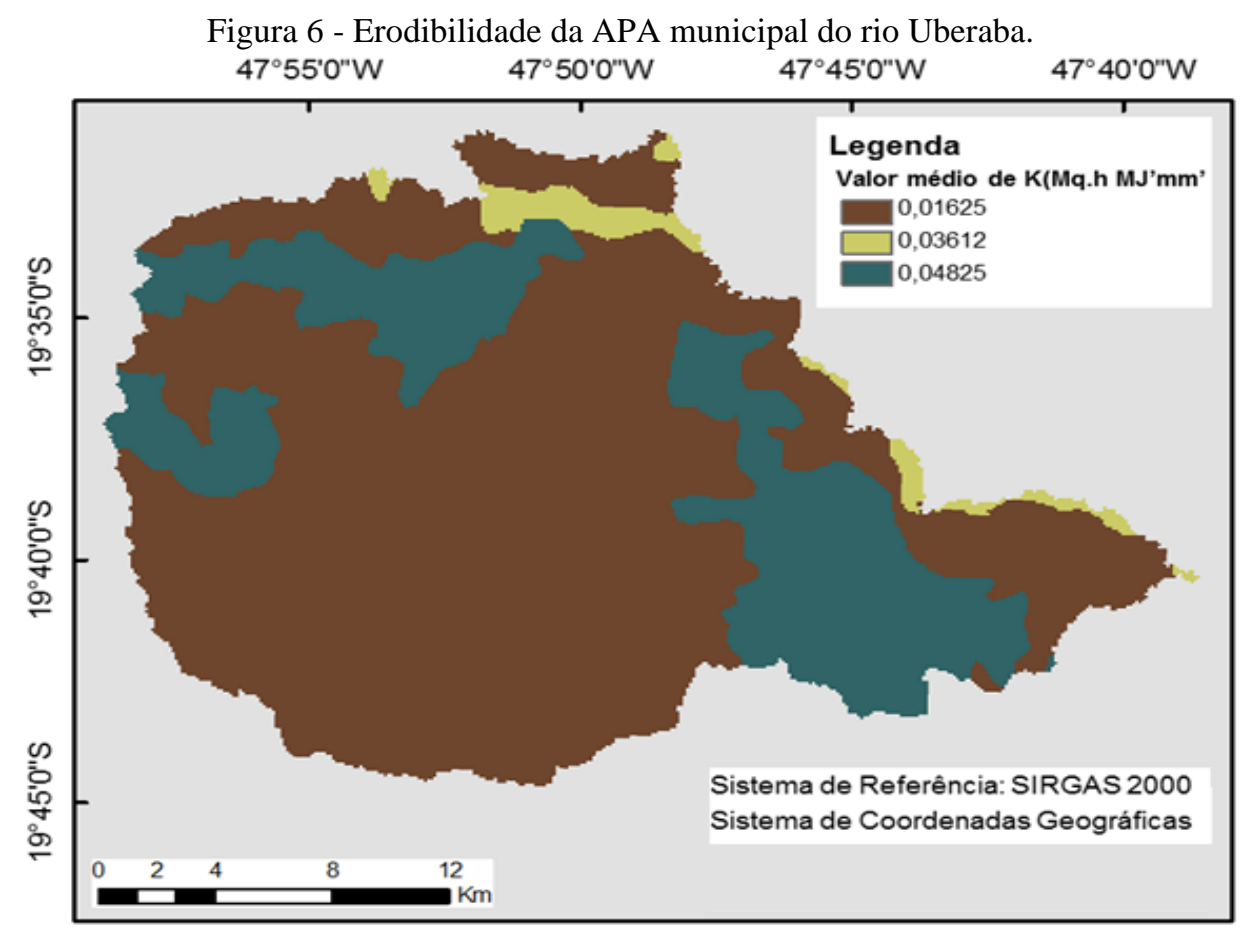

Fonte: Os autores (2021). 
Tabela 2 - Distribuição da erodibilidade em classes de interpretação.

\begin{tabular}{ll}
\hline Intervalos de valores de $\mathbf{K}$ & Classe de Interpretação \\
\hline $\mathrm{k}<0,02$ & Erodibilidade Baixa \\
$0,02<\mathrm{k}<0,038$ & Erodibilidade Média \\
$\mathrm{k}>0,038$ & Erodibilidade Alta \\
\hline
\end{tabular}

Fonte: Carvalho (1994) e Silva (2004) apud Matos (2015).

\subsection{Obtenção do mapa de uso e cobertura da terra na APA municipal do rio Uberaba}

O mapa de uso e cobertura da terra obtido pelo método de classificação supervisionada pixel-a-pixel utilizou um tamanho amostral 8.834 pixels distribuídos para as assinaturas espectrais das classes, conforme apresentado na Tabela 3 .

Tabela 3 - Classes amostrais para treinamento

\begin{tabular}{lc}
\hline \multicolumn{1}{c}{ Classes } & Número de pixels de treino \\
\hline Área urbana & 279 \\
Solo exposto 1 (tons de vermelho escuro) & 739 \\
Solo exposto 2 (tons de roxo) & 985 \\
Solo exposto 3 (tons de vermelho claro) & 1043 \\
Agricultura estágio inicial & 2932 \\
Agricultura estágio avançado & 1161 \\
Pastagem & 252 \\
Vegetação natural & 920 \\
Covoais & 523 \\
\hline
\end{tabular}

Fonte: Os autores (2021).

Tendo em vista que para o InVest 3.3.3 o uso e ocupação da terra deve estar em formato raster, na sua tabela de atributos é criada uma coluna, denominada LUCODE, com um código numérico inteiro para cada classe. A seguir é criada também uma tabela no formato (.csv), denominada tabela biofísica, apresentada na Tabela 4, que contém os valores do fator de cobertura do solo (fator C) e o fator de práticas conservacionistas (fator P) adotados para cada classe de uso da terra neste trabalho conforme sugerido por Valle Júnior (2008) para a área de estudo.

Tabela 4 - Tabela biofísica para a área de estudo. *Valle Júnior (2008)

\begin{tabular}{cccc}
\hline LULC & LUCODE & USLE_C* & USLE_P \\
\hline Área urbanizada & 1 & 0 & 0 \\
Solo exposto & 2 & 1 & 1 \\
Agricultura & 3 & 0.16370 & 1 \\
Pastagem & 4 & 0.05500 & 1 \\
Vegetação natural & 5 & 0.00522 & 0 \\
\hline
\end{tabular}

Fonte: Os autores (2021).

\section{RESULTADOS E DISCUSSÃO}

Os resultados e sua discussão são apresentados em três subseções. A primeira apresenta o mapa de uso e cobertura da terra para o cenário hipotético, a segunda apresenta o resultado do modelo e a terceira a discussão dos resultados encontrados.

\subsection{Uso e cobertura da terra na APA municipal do rio Uberaba em 2016}

Para validar o mapa de uso e ocupação da terra de 2016, foi gerada uma matriz de confusão e calculado o índice Kappa e a exatidão global, que apresentaram os resultados de $80 \%$ e $84 \%$, respectivamente. As classes que apresentaram maior confusão espectral entre si foram: solo exposto e área urbanizada, sendo que $20 \%$ dos pixels que deveriam ser atribuídos a essa classe área urbanizada foram imputados erroneamente à classe solo exposto. Outras classes que apresentaram confusão espectral significativa foram: solo exposto e área urbanizada (13\%), agricultura e pastagem (16\%), agricultura e vegetação natural (13\%), pastagem e agricultura $(13 \%)$. 
Figura 7 - Uso e cobertura da terra da APA municipal do rio Uberaba, ano 2016.

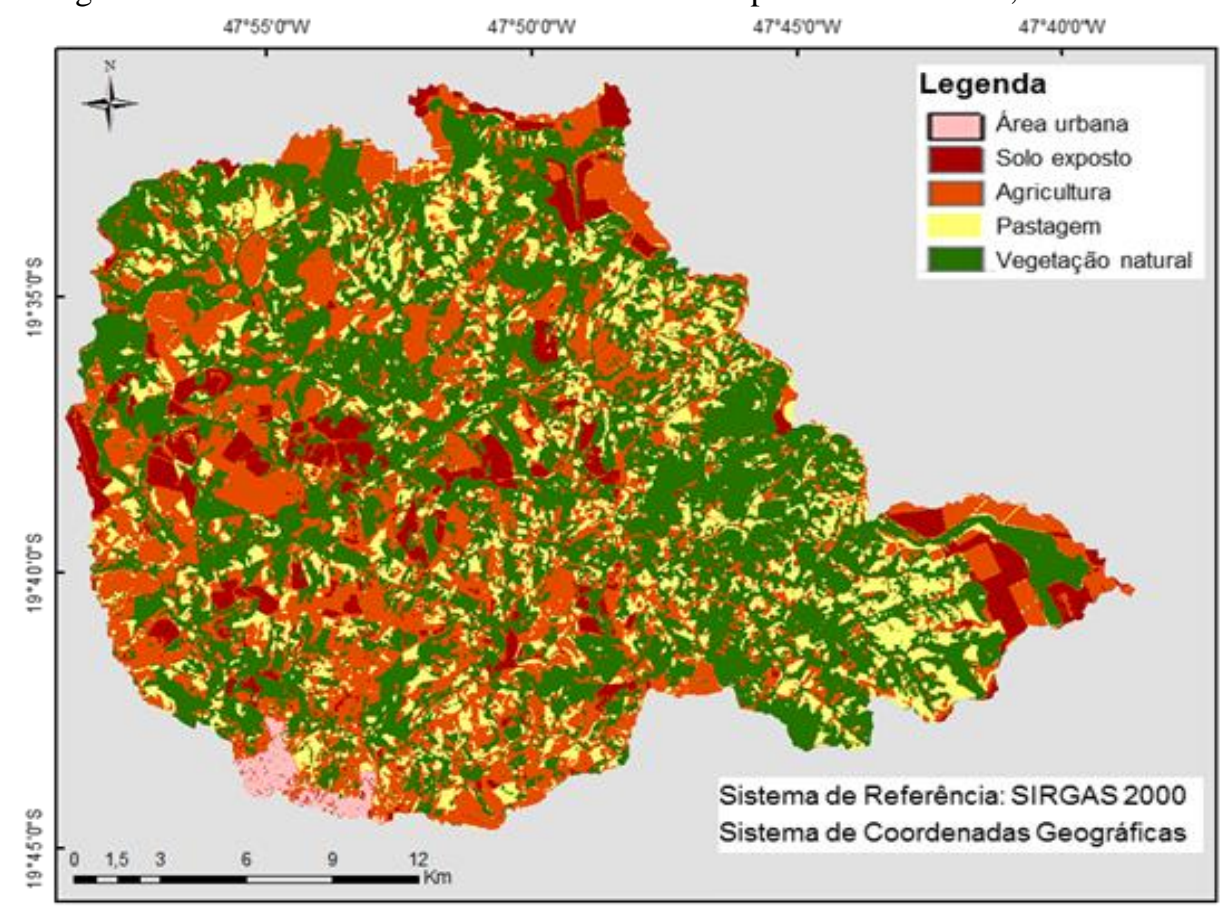

Fonte: Os autores (2021).

Para cada classe foi calculado a área em $\mathrm{km}^{2}$ e a porcentagem que cada classe representa dentro da APA municipal do rio Uberaba, conforme descrito na Tabela 5. Observa-se que a vegetação natural ocupa aproximadamente $43 \%$ da área, seguido de $31 \%$ de áreas agrícolas e $16 \%$ de áreas de pastagens. A menor ocupação é de área urbanizada.

Tabela 5 - Quantitativo das classes de uso e cobertura da terra para o ano de 2016.

\begin{tabular}{ccc}
\hline Classe & Área $\mathbf{( k m}^{\mathbf{2}} \mathbf{2}$ & Percentual \\
\hline Vegetação natural & 226,76 & $43,56 \%$ \\
Agricultura & 166,1 & $31,91 \%$ \\
Pastagem & 84,94 & $16,32 \%$ \\
Solo exposto & 38,1 & $7,32 \%$ \\
Área urbanizada & 4,7 & $0,90 \%$ \\
\hline Total & 520,6 & $100,00 \%$ \\
\hline
\end{tabular}

Fonte: Os autores (2021).

\subsection{Uso e cobertura da terra para o Cenário Hipotético}

O uso e cobertura da terra para o cenário hipotético foi criado substituindo os usos incompatíveis com as Áreas de Preservação Permanente (APPs), ou seja, agricultura e pastagem, por áreas de vegetação natural. A Figura 8 ilustra como seria o uso e cobertura da terra da APA municipal de Uberaba para o cenário hipotético, em que as APPs foram reflorestadas. Para cada classe foi calculado a área em $\mathrm{km}^{2}$ e a porcentagem que cada classe representa dentro da APA municipal do rio Uberaba (Tabela 6).

Tabela 6 - Quantitativo das classes de uso e cobertura da terra para o cenário hipotético.

\begin{tabular}{ccc}
\hline Classe & Área $\left(\mathbf{K m}^{2}\right)$ & Percentual \\
\hline Vegetação natural & 232,69 & $44,69 \%$ \\
Agricultura & 162,65 & $31,24 \%$ \\
Pastagem & 82,80 & $15,90 \%$ \\
Solo exposto & 37,79 & $7,26 \%$ \\
Área urbana & 4,69 & $0,90 \%$ \\
\hline Total & 520,63 & $100,00 \%$ \\
\hline
\end{tabular}

Fonte: Os autores (2021). 
Figura 8 - Uso e cobertura da terra da APA municipal do rio Uberaba para o cenário hipotético.

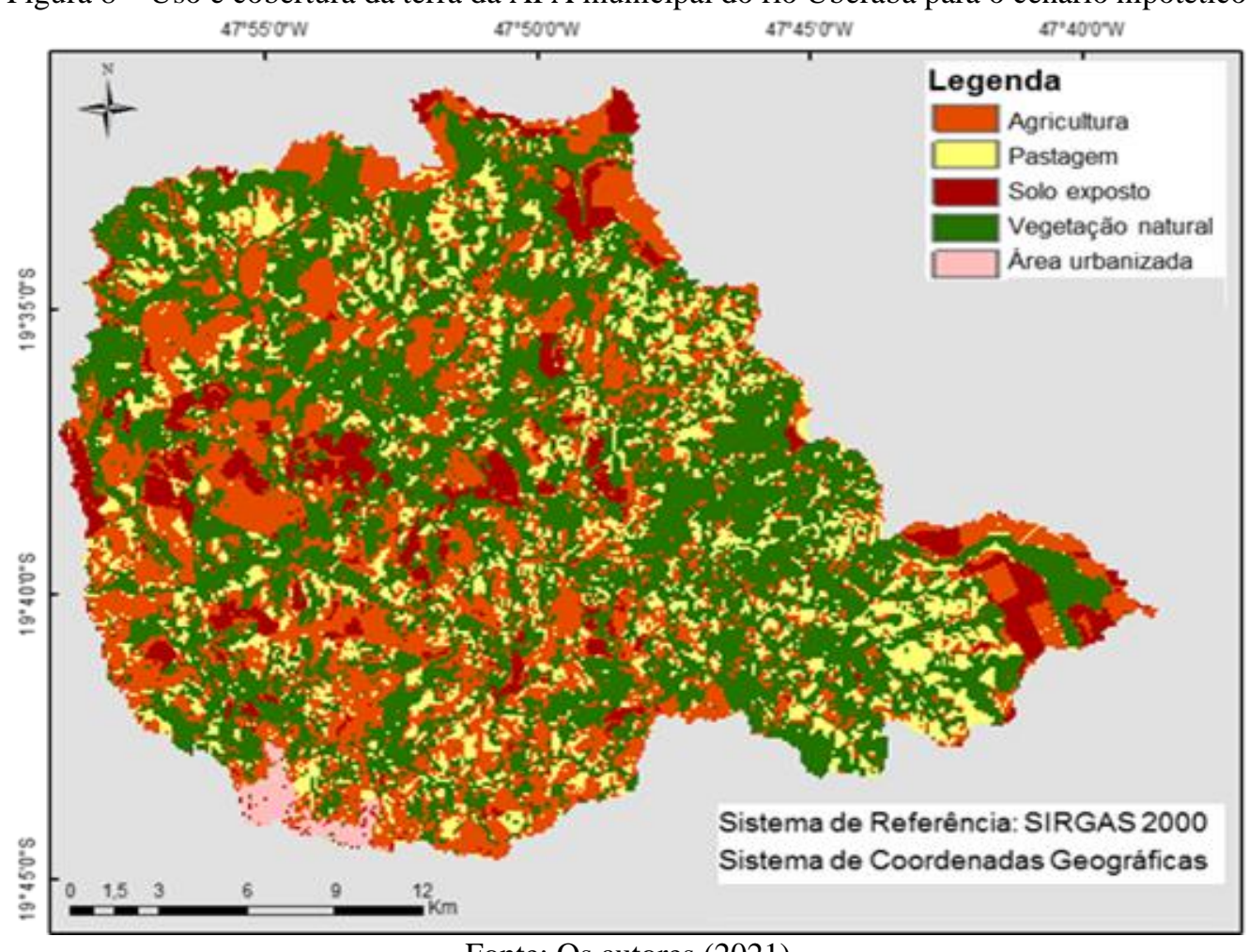

Fonte: Os autores (2021).

De acordo com o mapa de uso e cobertura da terra gerado para o cenário hipotético, há um déficit de APP de 1,13\%, cerca de $6 \mathrm{~km}^{2}$. Esse resultado demonstra que estas áreas se encontram antropizadas, sendo utilizadas possivelmente por agricultura e pastagem. A vegetação nativa presente nas matas ciliares visa minimizar o aporte de sedimentos para os leitos dos rios, sendo sua preservação imprescindível para manutenção da qualidade da água.

\subsection{Resultados do modelo}

O resultado do modelo de retenção de sedimentos realizada utilizando o programa InVEST 3.3.3, estão apresentados na Tabela 7 contendo valores biofísicos para cada bacia hidrográfica, com os seguintes atributos:

- Quantidade total de sedimentos exportados para o corpo hídrico por bacia hidrográfica (toneladas/ano): sed_export;

- Quantidade total de perda potencial de solo em cada bacia calculada pela equação USLE(toneladas/ano): usle_tot;

- Quantidade total de sedimentos retidos pela paisagem (toneladas/ano): sed_retent.

Para fins de análise, neste estudo, o resultado usle_tot (ton/ano) foi dividido pela área de cada microbacia para ter o resultado das perdas de solo em ton/ha.ano. Destes dados de saída do modelo foram gerados os mapas do potencial de perda de solo para o cenário atual (ano base 2016) e para o cenário hipotético, o mapa de exportação de sedimentos e o mapa de retenção de sedimentos apresentados e discutidos na seção a seguir. 
Tabela 7 - Resultado da modelagem do InVEST 3.3.3, módulo retenção de sedimentos

\begin{tabular}{|c|c|c|c|c|c|}
\hline Microbacias & $\begin{array}{c}\text { Area } \\
\text { (ha) }\end{array}$ & $\begin{array}{l}\text { sed_retent } \\
\text { (ton/ano) }\end{array}$ & $\begin{array}{c}\text { sed_export } \\
\text { (ton/ano) }\end{array}$ & $\begin{array}{c}\text { usle_tot } \\
\text { (ton/ano) }\end{array}$ & $\begin{array}{c}\text { Perda de solo } \\
\text { (ton/ha.ano) }\end{array}$ \\
\hline 1 & 2094 & 137830 & 3560 & 111494 & 53 \\
\hline 2 & 14 & 306 & 14 & 260 & 18 \\
\hline 3 & 206 & 5934 & 145 & 5296 & 26 \\
\hline 4 & 262 & 7676 & 113 & 6535 & 25 \\
\hline 5 & 40 & 779 & 11 & 437 & 11 \\
\hline 6 & 423 & 14653 & 683 & 17724 & 42 \\
\hline 7 & 252 & 5135 & 77 & 5119 & 20 \\
\hline 8 & 227 & 7077 & 387 & 15310 & 68 \\
\hline 9 & 280 & 6947 & 348 & 13110 & 47 \\
\hline 10 & 15 & 419 & 10 & 162 & 11 \\
\hline 11 & 735 & 17404 & 1434 & 43161 & 59 \\
\hline 12 & 162 & 30618 & 236 & 8661 & 53 \\
\hline 13 & 239 & 7506 & 313 & 6521 & 27 \\
\hline 14 & 627 & 12944 & 1399 & 49599 & 79 \\
\hline 15 & 827 & 47824 & 3082 & 120635 & 146 \\
\hline 16 & 828 & 19809 & 502 & 17445 & 21 \\
\hline 17 & 34 & 711 & 30 & 1001 & 30 \\
\hline 18 & 100 & 3455 & 54 & 1668 & 17 \\
\hline 19 & 223 & 5742 & 292 & 11848 & 53 \\
\hline 20 & 434 & 7397 & 263 & 11965 & 28 \\
\hline 21 & 99 & 2883 & 106 & 3042 & 31 \\
\hline 22 & 133 & 7976 & 116 & 3608 & 27 \\
\hline 23 & 431 & 17593 & 436 & 16417 & 38 \\
\hline 24 & 211 & 40174 & 384 & 12777 & 61 \\
\hline 25 & 436 & 8448 & 380 & 14914 & 34 \\
\hline 26 & 278 & 8523 & 45 & 2860 & 10 \\
\hline 27 & 154 & 12682 & 242 & 5263 & 34 \\
\hline 28 & 55 & 2699 & 19 & 535 & 10 \\
\hline 29 & 34 & 3532 & 15 & 206 & 6 \\
\hline 30 & 475 & 65635 & 489 & 18192 & 38 \\
\hline 31 & 275 & 10011 & 408 & 9809 & 36 \\
\hline 32 & 399 & 34307 & 232 & 13892 & 35 \\
\hline 33 & 61 & 3296 & 86 & 1764 & 29 \\
\hline 34 & 287 & 8437 & 149 & 6708 & 23 \\
\hline 35 & 288 & 6129 & 156 & 9387 & 33 \\
\hline Água Santa & 397 & 12277 & 197 & 8445 & 21 \\
\hline Alegria & 1488 & 41788 & 1381 & 41804 & 28 \\
\hline Barreiro & 1321 & 225042 & 1477 & 56805 & 43 \\
\hline Buracão & 2968 & 677978 & 5925 & 198593 & 67 \\
\hline Da Vida & 1494 & 290065 & 2547 & 91880 & 62 \\
\hline Inhame & 552 & 21766 & 409 & 18906 & 34 \\
\hline Lageado & 6690 & 162739 & 7112 & 198377 & 30 \\
\hline Lanhoso & 2121 & 106886 & 7669 & 211234 & 100 \\
\hline Limo & 923 & 22619 & 2128 & 46626 & 51 \\
\hline Mutum & 855 & 46560 & 803 & 32762 & 38 \\
\hline Pintos & 8381 & 803640 & 12338 & 401426 & 48 \\
\hline Sapecado & 753 & 179575 & 2116 & 54774 & 73 \\
\hline Saudade & 12481 & 1364900 & 18862 & 691106 & 55 \\
\hline
\end{tabular}

Fonte: Os autores (2021). 


\subsection{Discussão do resultado}

O resultado da modelagem para as microbacias da APA municipal do rio Uberaba utilizando o modelo de retenção de sedimentos do sistema InVEST 3.3.3 resultou em três mapas: i) mapa de perdas de solos em ton/ha.ano apresentado (Figura 9); ii) mapa da estimativa da exportação de sedimentos em ton/ano (Figura 10); e, iii) mapa da estimativa da retenção de sedimentos em ton/ano (Figura 11).

Figura 9 - Estimativa das perdas de solo (ton/ha.ano) nas microbacias da APA municipal do rio Uberaba.

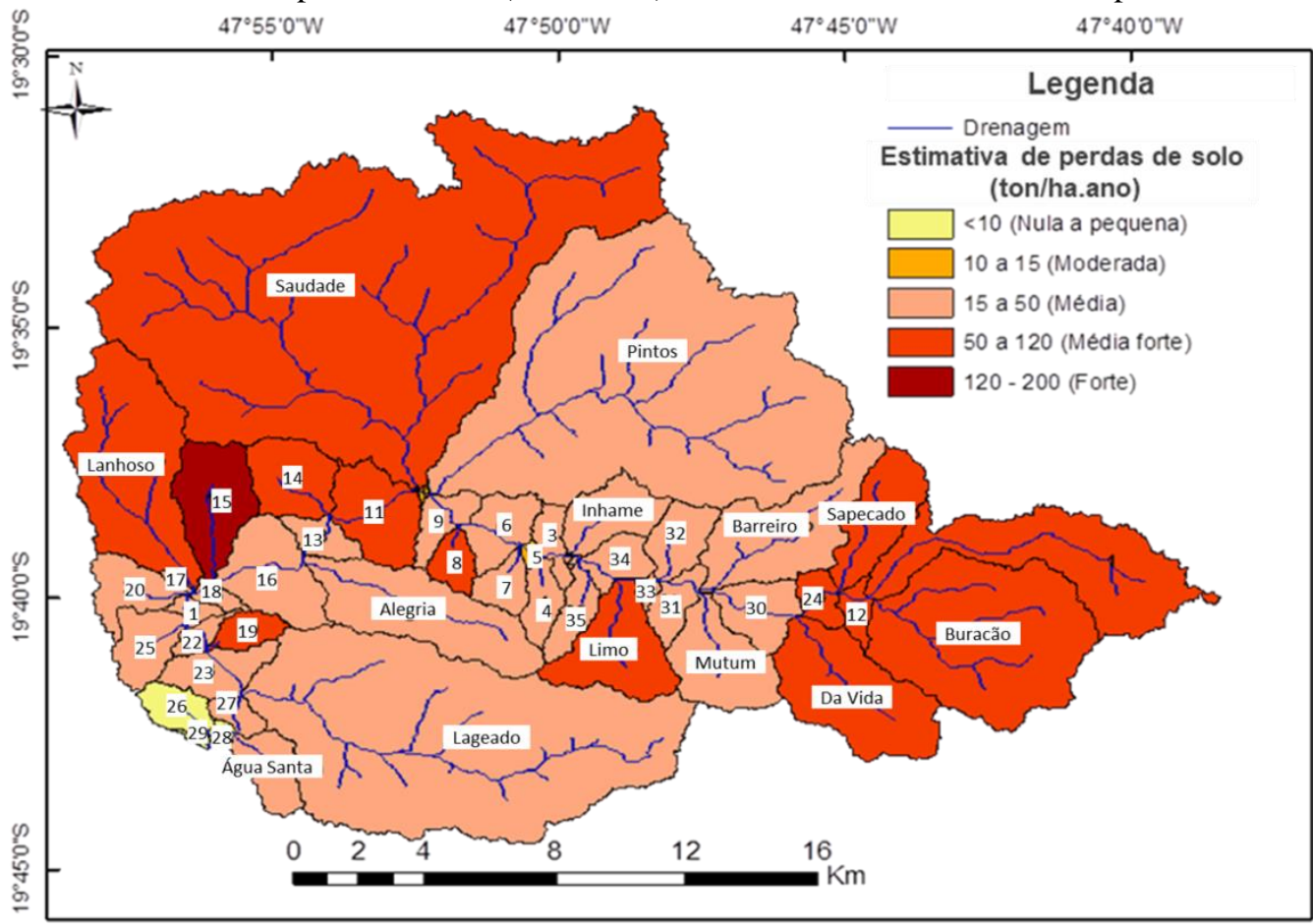

Fonte: Os autores (2021).

Figura 10 - Estimativa da retenção de sedimentos (ton/ano) nas microbacias da APA municipal do rio Uberaba.

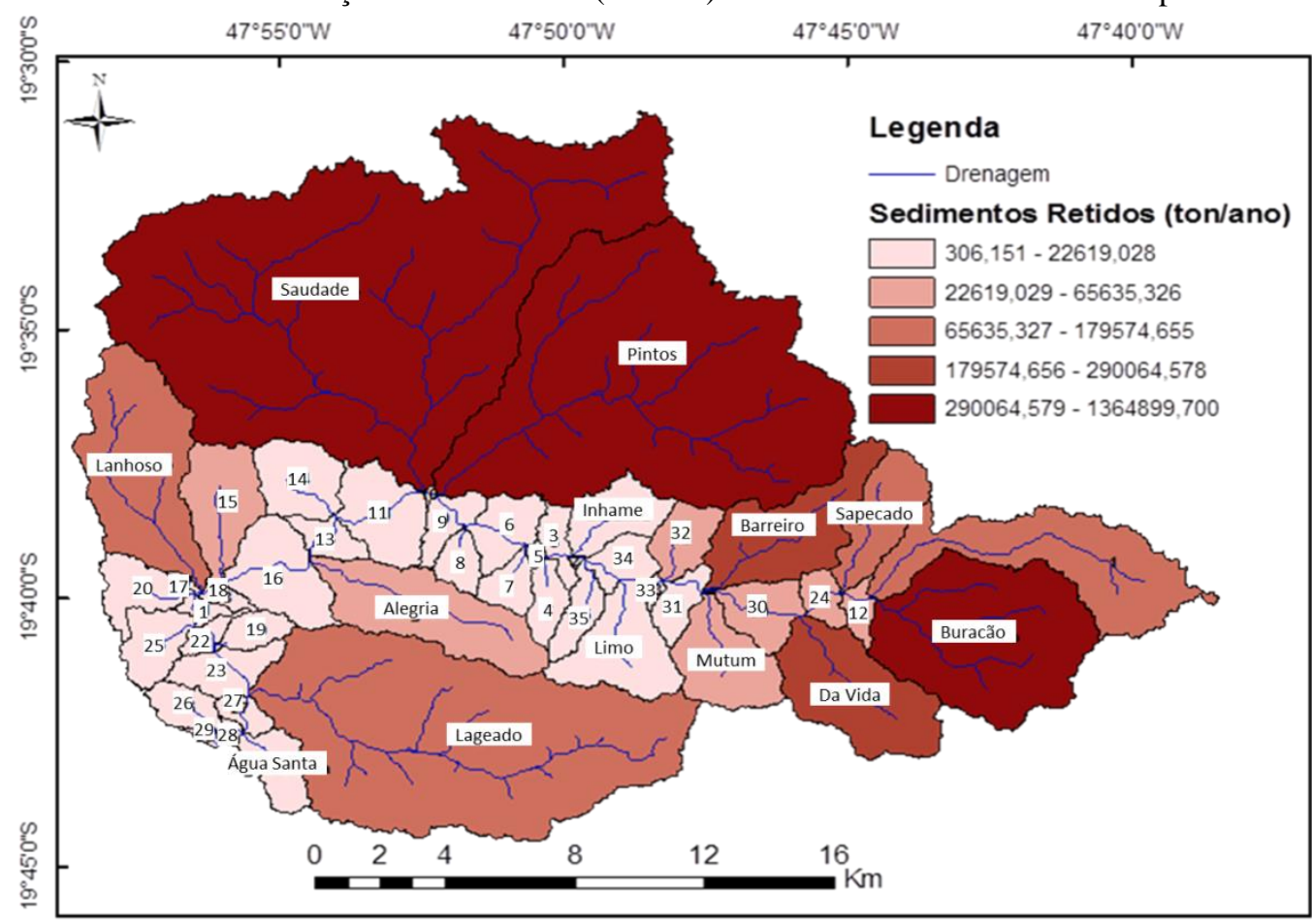

Fonte: Os autores (2021). 
Figura 11 - Estimativa da exportação de sedimentos (ton/ano) das microbacias para o rio Uberaba.

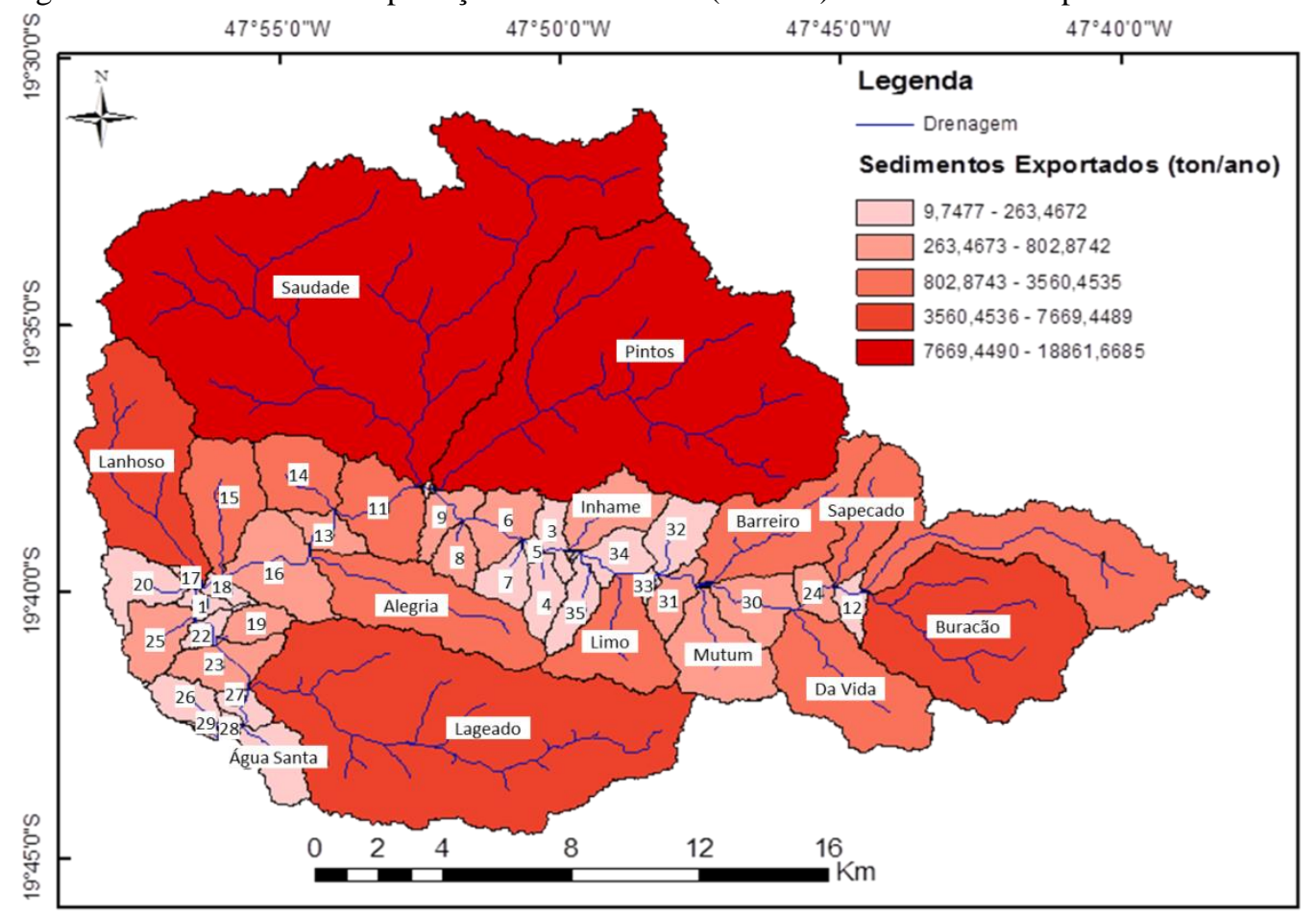

Fonte: Os autores (2021).

Os percentuais de perda de solo são apresentados na Tabela 8 descrevendo os níveis de erosão conforme a classificação proposta por Silva et al. (2003 apud VALLE JÚNIOR, 2008) e o potencial de perda de solo (colunas 1 e 2). Também são apresentados os resultados da modelagem por microbacia e o respectivo percentual (colunas 3 e 4). Observa-se na Tabela 8 que a microbacia 15 foi a única que apresentou o nível da erosão classificada como forte. No resultado da modelagem, a estimativa de perda de solo para essa microbacia foi de 146 ton/ ha.ano, valor 9 vezes acima da média de um terreno de um hectare desprovido de vegetação, que perde 16 ton/ ha.ano (BARRELA et al.,2009).

Tabela 8 - Percentual de perda de solo por microbacias.

\begin{tabular}{llll}
\hline Nível da erosão & $\begin{array}{l}\text { Potencial de perda de } \\
\text { Solo (ton/ha.ano) }\end{array}$ & Microbacias & Percentual (\%) \\
\hline Nula a pequena & $<10$ & 26,28 e 29 & $6,25 \%$ \\
Moderada & 10 a 15 & 5 e 10 & $4,17 \%$ \\
Média & 15 a 50 & $2,3,4,6,7,9,13,16,17,18,20,21,22,23,25,27,30,31,32,33$, \\
& & 34,35, Pintos, Barreiro, Mutum, Inhame, Lageado, Alegria e Água & $60,42 \%$ \\
Média forte & 50 a 120 & Santa & $27,08 \%$ \\
& & $1,8,11,12,14,19,24$, Lanhoso, Sapecado, Buracão, Da Vida, & $2,08 \%$ \\
Forte & 120 a 200 & Saudade e Limo & \\
\hline
\end{tabular}

Fonte: Os autores (2021).

De acordo com o Zoneamento da APA municipal do Rio Uberaba apresentado por Mauro et al. (2015), a microbacia 15 é uma zona agropecuária, o que pode estar contribuindo para o elevado valor de perdas de solo é o uso da terra. Conforme o mapa de uso e cobertura da terra confeccionado para este trabalho (ano base 2016), na microbacia 15 , cerca de $39 \%$ da microbacia é ocupada por agricultura e $21 \%$ de solo exposto. De acordo com Guerra (2012), a erosão pode ser intensificada quando a estação chuvosa ocorre no período em que os solos se encontram descobertos, ou por uma colheita anterior a essa estação, ou por um plantio recente. A adoção de práticas conservacionistas do uso do solo poderia contribuir para reduzir o valor de perdas de solo nesta microbacia.

As microbacias do Ribeirão Saudade e Córrego dos Pintos correspondem a 40\% da área total da APA 
municipal do rio Uberaba e apresentaram respectivamente as maiores estimativas para retenção, 1.364.899,70 ton/ano e 803.639,9084 ton/ano (Figura 10). A vegetação natural dessas duas microbacias são as que têm contribuído mais para o fornecimento do serviço de retenção de sedimentos. As microbacias do Ribeirão Saudade e Córrego dos Pintos também são responsáveis pelas maiores taxas de exportação de sedimentos, 18.861,66 ton/ano e 12.337,96 ton/ano, respectivamente (Figura 11).

O serviço de retenção de sedimentos fornecido pela vegetação natural é de grande interesse para as companhias de água, pois compreender onde os sedimentos são produzidos e depositados permitem criar estratégias para reduzir as cargas de sedimentos exportadas para os leitos dos rios. Caso fossem adotadas ações de recomposição das APPs, nas microbacias do Ribeirão Saudade (28\%), Lanhoso (14\%), Pintos (13\%), Lageado e microbacia $15(8 \%)$ e microbacia 1 (7\%) teriam uma diminuição representativa nas perdas de solo.

De acordo com a modelagem do sistema InVEST, o total de sedimentos estimados pelas microbacias que compõem a APA municipal do rio Uberaba em 2016 foi de 2.620 .062 ton/ano e para o cenário futuro foi de 1.258.989 ton/ano. Esse resultado indica que a recuperação de cerca de $6 \mathrm{~km}^{2}$ de APPs pode reduzir a geração de sedimentos em $48 \%$.

\section{CONSIDERAÇÕES FINAIS}

O InVEST é uma importante ferramenta para criação de cenários, em que, através da modelagem é possível estimar os serviços ambientais, como por exemplo o controle da erosão, quando se adota ações conservacionistas e a recomposição florestal das APPs. A modelagem para o cenário hipotético, em as APPs se encontram reflorestadas, houve uma redução de $48 \%$ de perdas de solo nas microbacias da APA municipal do rio Uberaba. Assim, neste estudo foi possível demonstrar quantitativamente as perdas de solo que poderiam ser evitadas com a recomposição das APPs, representando a importância que a vegetação ripária exerce na provisão dos serviços ambientais de controle da erosão.

Neste trabalho, a microbacia do Córrego Lanhoso foi considerada uma área crítica, necessitando prioritariamente da implantação de ações de recuperação das áreas de preservação permanente e práticas conservacionistas do uso e manejo do solo, pois apesar da sua área ocupar cerca e $4 \%$ da área total da APA municipal do rio Uberaba, essa microbacia apresentou a segunda maior estimativa de perda de solo em ton/ha.ano e a terceira que exporta mais sedimentos para o leito do rio Uberaba. De acordo com o resultado da modelagem do cenário hipotético, com a recomposição das APPs haveria uma redução de $14 \%$ nas perdas de solo nessa microbacia. Outro fator que demanda atenção é que $42 \%$ dessa microbacia é composta por Argissolo, que possui alta erodibilidade. De acordo com Conceição (2014) para monitoramento da qualidade da água, a análise da exportação de sedimentos total de cada microbacia é a que deve ser levada em consideração para priorizar ações.

Apesar dos benefícios apresentados pela ação de reflorestamento das APPs, principalmente em relação à diminuição das perdas de solo, cabe ressaltar que um programa de PSA deve ser implementado levando em consideração as relações socioecológicas locais. Assim, deve ser feito um intenso trabalho de educação ambiental com os produtores rurais a fim de se afastar a cultura de que é pagando que se preserva, uma das preocupações de vários estudiosos, que podem levar ao fracasso dos programas de PSA.

\section{Contribuição dos Autores}

A primeira autora foi responsável pela curadoria dos dados, análise formal, investigação, metodologia, recursos, software, visualização e redação em todos os níveis (minuta inicial, revisão e edição). A segunda autora contribuiu com a conceptualização, visualização, supervisão e redação (revisão e edição). $O$ terceiro autor auxiliou na conceptualização, investigação, supervisão e redação em todos os níveis.

\section{Conflitos de Interesse}

Os autores declaram que não há conflito de interesses. 


\section{Referências}

ABDALA, V. L.; TORRES, J. L. R.; BARRETO, A. C. Análise hidrológica das nascentes do alto curso do rio Uberaba. Caminhos de Geografia, Uberlândia, v. 10, p. 171-183, 2009.

BARRELLA, W. PELTRERE JR., M.; SMITH, W.S.; MONTAG, L. F. A. As relações entre as matas ciliares, os rios e os peixes. In: RODRIGUES, R. R.; LEITÃO FILHO, H. (Editores). Matas Ciliares: Conservação e Recuperação. 2 ed. 2 reimpr. São Paulo: Editora da Universidade de São Paulo, Fapesp, 2009. 187-207.

CÂNDIDO, H. G.; GAlBIATTI, J. A.; PISSARRA, T. C. T.; MARTINS FILHO, M. V. Degradação ambiental na bacia hidrográfica do rio Uberaba: uma abordagem metodológica. Engenharia Agrícola, v. 30, n. 1, p. 179-192, 2010.

CODAU - Centro Operacional de Desenvolvimento e Saneamento de Uberaba. Projeto Água Viva Relatório de Avaliação Ambiental. Uberaba, Brasil, 2005, 416 p.

CONCEIÇÃO, J. R. Metodologia para identificação de áreas prioritárias para redução da erosão hídrica em bacias de mananciais de abastecimento público do Paraná: Estudo de caso do Passaúna. 2014. 94 f. Dissertação (Mestrado profissional) - Universidade Federal do Paraná, Setor de Tecnologia, Programa de Pós-Graduação em Meio Ambiente Urbano e Industrial, SENAI -PR, Universitat Stuttgart, Curitiba, 2014.

FERRARO, P. J. The Future of Payments for Environmental Services. Conservation Biology, v. 25, n. 6, p. 1134-1138, 2011.

GARRASTAZU, M. C.; AUGUSTA, M.; ROSOT, D. Uso do gvSIG como apoio a mapeamentos de solos. In: JORNADAS BRASILEIRAS DE GVSIG, 3., 2012, São Paulo, Brasil. Anais... 2012, São Paulo, Brasil. Disponível em: < http://ainfo.cnptia.embrapa.br/digital/bitstream/item/72127/1/2012-Marilice-JBgvSIGUso.pdf>. Acesso em: 17 ago. 2015.

GUERRA, A. J. T. O início do processo erosivo. In: GUERRA, A. J. T.; SILVA, A. S.; BOTELHO, R. G. M. (Editores). Erosão e Conservação dos Solos: conceitos, temas e aplicações. $7^{a}$ ed. Rio de Janeiro: Bertrand Brasil, 2012. 17-50.

MATOS, T. V. S. Determinação de áreas de vulnerabilidade à erosão hídrica com base na equação universal de perda de solo (USLE). $116 \mathrm{f}$. Dissertação (Mestrado). Universidade Federal de Minas Gerais, Programa de Pós-graduação em Saneamento, Meio Ambiente e Recursos Hídricos, 2015.

MAURO, L. M.; CASTRO, K. J. S. X.; CAMPOS, I. C. C. RODRIGUES, N. U. A. VALERA, C. A. Desafios na delimitação do zoneamento da Área de Proteção Ambiental do rio Uberaba (Uberaba/MG). In: I SIMPÓSIO INTERNACIONAL DE ÁGUAS, SOLOS E GEOTECNOLOGIAS, 2015, Uberaba, Minas Gerais, Brasil. Anais do I Simpósio Internacional de Águas, Solos e Geotecnologias, 2015, Uberaba, Minas Gerais, Brasil. Disponível em https://institutopristino.org.br/wpcontent/uploads/2020/04/ResumoIII.pdf. Acesso em 12 jul. 2017

MOREIRA, M. C.; PRUSKI, F.F. OLIVEIRA, T. E. C.; PINTO, F. A. C, SILVA, D. D. NetErosividade MG: erosividade da chuva em Minas Gerais. Revista Brasileira de Ciência do Solo, v. 32, p.1349-1353, 2008.

MURADIAN, R.; CORBERA, E.; PASCUAL, U.; KOSOY, N.; MAY, P. H. Reconciling theory and practice: An alternative conceptual framework for understanding payments for environmental services. Ecological Economics, v. 69, n. 6, p. 1202-1208, 2010.

PEDROSO NETO, J. C.; COSTA, J. O. Caracterização química e física dos murundus da nascente do rio Uberaba. FAZU em Revista, Uberaba, n.7, p. 27- 31, 2010.

OLIVEIRA, M.S.M. Rio Uberaba: quando os desgastes ambientais refletem os desgastes sociais. $176 \mathrm{f}$. Dissertação (Mestrado em Geografia), Programa de Pós-Graduação em Geografia. Universidade Federal de Uberlândia, 2005.

PLANCHON, O., DARBOUX, F. 2002. A fast, simple and versatile algorithm to fill the depressions of digital 
elevation models. Catena 46(2): 159-176.

QUINTERO, M. Servicios ambientales hidrológicos en la Región Andina. Estado del conocimiento, la acción y la política para asegurar su provisión mediante esquemas de pago por servicios ambientales. Lima, IEP; CONDESAN, 2010. (Agua y Sociedad, 12; Serie Panorama Andino.

RABELLO, T. S. Avaliação da efetividade da conservação da cobertura vegetal do Parque Nacional da Serra da Bocaina através do sensoriamento remoto. 164f. Dissertação (mestrado) - Instituto de Pesquisas Jardim Botânico do Rio de Janeiro, Escola Nacional de Botânica Tropical, Mestrado Profissional em Biodiversidade em Unidades de Conservação, 2016.

STANFORD UNIVERSITY. Ferramenta computacional. Software InVEST® versão 3.3.3, Stanford, CA. 2013. Home page. Disponível em: <http://naturalcapitalproject.org/download.html>. Acesso em: 11 jun. 2015.

THOMPSON, D.; FIDALGO, E.C.C. Estimativa da perda de solos por meio da equação universal de perdas de solos (USLE) com uso do InVEST para a bacia hidrográfica do rio Guapi-Macacu - RJ. In: Simpósio Brasileiro de Recursos Hídricos, 2013, Bento Gonçalves. Anais... Disponível em: < http://ainfo.cnptia.embrapa.br/digital/bitstream/item/97697/1/Thompson-e-Fidalgo.pdf>. Acesso em: 17 ago.2015.

UBERABA. Plano de Manejo da APA do Rio Uberaba. Secretaria de Meio Ambiente. Uberaba, Brasil, set. 2004. $112 \mathrm{p}$.

UBERABA. Plano de Manejo da APA do Rio Uberaba. Secretaria de Meio Ambiente. Uberaba, Brasil, set. 2012. $155 \mathrm{p}$.

UFV - CETEC - UFLA - FEAM. Mapa de solos do Estado de Minas Gerais. Belo Horizonte, Fundação Estadual do Meio Ambiente, 2010. 49p. Disponível em: <http://www.feam.br/noticias/1/949-mapas-desolo-do-estado-de-minas-gerais >. Acesso em: 02 abr. 2017

VALLE JUNIOR, R. F. Diagnóstico de áreas de risco de erosão e conflito de uso dos solos na bacia do rio Uberaba. 222f. Tese (doutorado) - Universidade Estadual Paulista, Faculdade de Ciências Agrárias e Veterinárias, 2008.

WUNDER, S. When payments for environmental services will work for conservation. Conservation Letters, v. 6, n. 4, p. 230-237, 2013.

ZANELLA, B. P. Modelagem do aporte de sedimentos aplicada à bacia hidrográfica contribuinte da PCH Costa Rica (MS) e proposta de mitigação do assoreamento. 142f. Tese (Doutorado). Universidade Estadual Paulista, Faculdade de Engenharia de Guaratinguetá, 2016.

ZOLIN, C. A. Análise e otimização de projetos de Pagamentos por Serviços Ambientais (PSA) utilizando Sistemas de Informações Geográficas (SIG) - o caso do município de Extrema, MG. 130f. Tese (doutorado) Universidade de São Paulo, Escola Superior de Agricultura Luiz de Queiroz, 2010.

\section{Biografia do autor principal}

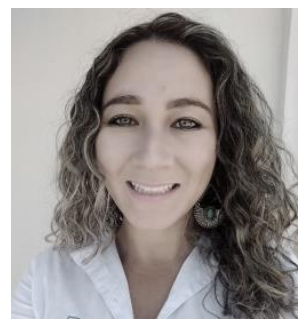

Aline Claro de Oliveira, Uberaba/MG, Brasil, 1986. Doutoranda em Ecologia e Conservação dos Recursos Naturais pela Universidade Federal de Uberlândia (UFU) de 2020 até o momento, Mestre em Engenharia Ambiental pela UFRJ em 2017, Especialista em Análise Ambiental e Gestão do Território pela Escola Nacional de Ciências Estatísticas do IBGE em 2017, Engenheira de Segurança do Trabalho pela Universidade Católica de Petrópolis em 2016, Engenheira Ambiental pela Universidade de Uberaba (Uniube) em 2012. 